Original Article

\title{
Knowledge about informed consent among doctors in postgraduate courses in Bangladesh
}

\author{
Kazi Taib Mamun ${ }^{1}$, Nabeela Mahboob ${ }^{2}$, Mohammad Abdullah Al Mahmud ${ }^{3}$, K. Zaman $^{1}$ \\ ${ }^{1}$ Infectious disease division, icddr, b, Dhaka, Bangladesh; ${ }^{2}$ Department of Microbiology, Popular Medical \\ College, Dhaka, Bangladesh; ${ }^{3}$ Nutrition and Clinical Sciences Division, icddr, b, Dhaka, Bangladesh
}

\begin{abstract}
Background and objectives: Informed consent is now accepted as the cornerstone of medical practice and research. Concept of consent is an endeavor by which the patient can take part in clinical judgment concerning their treatment and protects patient and doctors against any litigation. However, in research informed consent is not merely a form that is signed, but is a process in which the participant has an understanding of the research and its risks. In view of this, the objective of the study was to assess the knowledge regarding informed consent among the doctors pursuing postgraduate courses in a medical institute in Bangladesh.
\end{abstract}

Methodology: A descriptive cross sectional study was carried out among 160 postgraduate medical students in Dhaka city. A self-administered structured questionnaire consisting of 36 questions was used to assess their knowledge regarding informed consent. The response format was based on a 3-point Likert scale. Frequency distribution was used for statistical analysis.

Results: The age range of the participants was from $25-40$ years. Of the total participants, $48 \%$ were males and $42 \%$ were females. Majority of the respondents acknowledged the importance of an informed consent and $86.3 \%$ of the doctors agreed that only verbal consent was not adequate. Only $66.2 \%$ agreed that consent for participation in research should always be voluntary and informed. Majority (76.9\%) agreed not to recruit individuals with mental or behavioral disorders not capable of giving adequately informed consent. Only $27.5 \%$ were aware that assent should be taken from children participating in a research. Out of total participants, $71.2 \%$ and $81.2 \%$ agreed that the participants should be informed about the laboratory test results. Management/referral must be ensured in case of abnormal test results respectively. For genetic research, $88.1 \%$ and $81.3 \%$ agreed for pre- and post-counseling respectively.

Conclusion: There is need to initiate further educational programs to aware the doctors of the importance of informed consent in research, clinical practice and patient care.

IMC J Med Sci 2020; 14(1): 005. EPub date: 07 March 2020

\section{Introduction}

Medical research has increased greatly in many developing countries during the recent decade, motivated by the need to improve health in these countries [1]. Since medical research involves human participants, such research needs to be guided by fundamental ethical principles to ensure the protection of their rights and welfare. Furthermore, international standards mandate the review of research by research ethics committees (RECs) $[2,3]$.

The concept of consent in medicine came from ethics and the Hippocratic Oath is one of the ancient forms of medical ethics. Consent is a deliberate concord between doctor and patient,

\section{Address for Correspondence:}

Dr. Nabeela Mahboob, Assistant Professor, Department of Microbiology, Popular Medical College, Dhanmondi, Dhaka, Bangladesh. Email: nabeela.islam311@gmail.com, Contact no: 01769050442 
and in health care sector, it gives moral values to maintain the dignity of profession [4]. The foundation of medical ethics was laid at the Hippocrates School (400-300 BC) and since then the idea has revolutionized through different stages [5]. Contemporary medical ethics and bioethics began after the World War II as a result of contemptible issues in medical research and medical interventions $[5,6]$.

Ethical code within medicine has evolved overtime. In the past, a "doctor knows best" attitude was adopted by patients before any procedure as universal acceptance of the physician's procedure. It was in the last few centuries that pressure began to mount on physicians for information about diseases and treatment options by patients [7]. The Nuremberg Trials of 1947 are regarded as the basis for the development of medical consent [8]. The Nuremberg Code of 1948 laid out the principle that "voluntary consent of the human subject is absolutely essential" [9]. Informed consent eventually emerged as legal and a right in 1972. This was as a result of series of legal cases in California in the 1950s [10] and in response to public outcry concerning unethical practices in the Tuskegee research [7]. Informed consent is a legal term that is supported by jurisdiction and international laws. It is defined as "voluntary agreement given by a person or a patient's responsible proxy for participation in a study, immunization program, treatment regimen, invasive procedure, etc., after being informed of the purpose, methods, procedures, benefits and risks" [11].

Informed consent is an essential tool of standard ethical medical practice. It is the process of sharing information with patients that is essential to their ability to make rational choices among multiple options in their perceived best interest [12]. It is universally recognized as an essential safeguard to ensure the preservation of individual's rights [13]. In current daily practice, medical researcher comes across common ethical issues. The core issues in medical ethics are the ethics of the doctor-patient relationship, patient's confidentiality, and the need to obtain informed consent, whereas bioethics deals with all-encompassing moral issues in medicine and biomedical sciences [14,15]. Several professional organizations and government entities have recognized the importance of consents by issuing guidelines for informed consents $[16,17]$
Most likely the current infrastructure in medical institutions in Bangladesh is not sufficient to deal with the problems. It is necessary to assess the knowledge of the students who are at the initial stages of ethical practice in research. In view of this, the present study was conducted to explore the knowledge about informed consent of doctors pursuing postgraduate courses in an institute in Dhaka city.

\section{Study design and procedure}

A descriptive cross-sectional study was conducted among postgraduate medical doctors over a three months' period from January 2018 to March 2018. The study was conducted in a single Postgraduate Medical Institute. All doctors of different disciplines studying in $2^{\text {nd }}$ year and thesis part of postgraduate courses were approached to take part in the present study. Only 160 doctors agreed to take part and after obtaining consent a self-administered structured questionnaire was distributed. The questionnaire was developed and tested among them, and interviewed to obtain feedback on the overall acceptability of the questionnaire in terms of length and language clarity. Based on their feedback, the questionnaire did not require any corrections. The questionnaire designed to obtain knowledge towards informed consent, consisted of four sections. Section I solicited general demographic and professional background information. Section II had integrated 24 questions to collect information about knowledge regarding informed consent, section III had integrated 8 questions about knowledge regarding informed assent and section IV had integrated 4 questions about knowledge towards genetic studies. Before giving the questionnaires the participants were clearly explained about the research procedure and purpose. The anonymity was maintained. They were approached individually and requested to complete the forms. The participant's responses for all sections other than section I were recorded using a 3-point Likert scale. Questionnaires were coded and excel sheet was created for data entry. The data were analyzed using SPSS version 20 (SPSS Inc., Chicago, IL, USA). Frequency distribution was calculated for proportion. 


\section{Results}

All the participants were medical graduates and they were studying for postgraduate degree in different specialty. The age range of the participants was from 25-40 years. Of the total participants, about $48 \%$ were males while $42 \%$ were females. Table-1 shows that $90 \%$ of the medical professionals acknowledged the importance of an informed consent and $86.3 \%$ of the doctors agreed that only verbal consent should not be taken. Only $5 \%$ agreed that verbal consent was the favorable method to obtain informed consent. Of the total respondents, 92.5\% agreed that informed consent was to be designed to empower the individual with information to make a voluntary informed decision regarding participation in a research. Most (89.4\%) agreed that consent should be taken from adults. Though only $66.2 \%$ agreed in the present study that consent for participation in research should always be voluntary and informed. Majority (76.9\%) agreed that efforts should be made not to recruit individuals who were not capable of giving adequately informed consent by reason of mental or behavioral disorders and $75.6 \%$ agreed that guardians might give consent for individuals with temporary disability. Out of total participants, $71.2 \%$ agreed that the participants should be informed about the laboratory test results that influence the immediate outcome/management of the health problem of study participants and $81.2 \%$ agreed that management/referral must be ensured in case of abnormal test results. In the present study, $68.8 \%$ agreed that in long term studies where repeated data collection was required, the participants should be re-consented at two years' interval, even if there were no changes in the design or objectives of the research. Table-2 shows that only $27.5 \%$ were aware that assent should be taken from children participating in a research when $95.6 \%$ agreed that consent should be sought from parents/guardians in case of research with children below the age of 11 years.

Table-3 shows that about $82 \%$ of the participants agreed that for genetic studies, participants should be informed about the nature, outcome and consequences of the study findings; test results must be revealed and clarified. For genetic research, $88.1 \%$ and $81.3 \%$ agreed for pre- and post-counseling respectively.

Table-1: Knowledge regarding informed consent among doctors pursuing postgraduate courses in different specialties

\begin{tabular}{|c|c|c|c|c|}
\hline SL & Knowledge & $\begin{array}{l}\text { Agree/ } \\
\text { Yes }\end{array}$ & $\begin{array}{l}\text { Disagree/ } \\
\text { No }\end{array}$ & $\begin{array}{l}\text { Neutral/ } \\
\text { Not sure }\end{array}$ \\
\hline 1 & $\begin{array}{l}\text { Consent form is a contract between the researcher } \\
\text { and participant }\end{array}$ & $144(90 \%)$ & $9(5.6 \%)$ & $7(4.6 \%)$ \\
\hline 2 & $\begin{array}{l}\text { Consent form is used to protect- } \\
\text { researcher and participant }\end{array}$ & $124(77.5 \%)$ & $10(6.2 \%)$ & $26(16.3 \%)$ \\
\hline 3 & Consent is must for human research & $154(96.3 \%)$ & $1(0.6 \%)$ & $5(3.1 \%)$ \\
\hline 4 & Only verbal consent is taken & $8(5 \%)$ & $138(86.3 \%)$ & $14(8.7 \%)$ \\
\hline 5 & Signed written consent is a must & $137(85.6 \%)$ & $12(7.5 \%)$ & $11(6.9 \%)$ \\
\hline 6 & Consent is taken from adult participants & $143(89.4 \%)$ & $13(8.1 \%)$ & $4(2.5 \%)$ \\
\hline 7 & $\begin{array}{l}\text { Informed consent is to be designed to empower the } \\
\text { individual with information to make a voluntary } \\
\text { informed decision regarding participation in a } \\
\text { research }\end{array}$ & $148(92.5 \%)$ & $3(1.9 \%)$ & $9(5.6 \%)$ \\
\hline
\end{tabular}




\begin{tabular}{|c|c|c|c|c|}
\hline 8 & $\begin{array}{l}\text { The consent must ensure 'Respect of the autonomy' } \\
\text { and self-determination of all human beings, and } \\
\text { acknowledge their dignity and freedom }\end{array}$ & 150 (93.8\%) & $1(0.6 \%)$ & $9(5.6 \%)$ \\
\hline 9 & $\begin{array}{l}\text { Informed consent recognizes the capacity and rights } \\
\text { of all individuals to make their own choices and } \\
\text { decisions }\end{array}$ & $140(87.5 \%)$ & $4(2.5 \%)$ & $16(10 \%)$ \\
\hline 10 & $\begin{array}{l}\text { The principles of informed consent and voluntary } \\
\text { participation are cardinal elements to be observed } \\
\text { throughout the research experiments, including its } \\
\text { aftermath }\end{array}$ & 121 (75.6\%) & $12(7.5 \%)$ & 27 (16.9\%) \\
\hline 11 & $\begin{array}{l}\text { Research participants are to be continually kept } \\
\text { informed of any and all developments in so far as } \\
\text { they affect them and others }\end{array}$ & $113(70.6 \%)$ & $24(15 \%)$ & $23(14.4 \%)$ \\
\hline
\end{tabular}

12 Consent for participation in research is voluntary and $106(66.2 \%) \quad 18(11.3 \%) \quad 36(22.5 \%)$ informed only if it is given without any direct/indirect coercion and inducement, and is based on adequate briefing given to the participants about the details of the project

13 The language of consent form should be consistent $\quad 155(96.9 \%) \quad 3(1.9 \%) \quad 2(1.2 \%)$
with the level of understanding of the specific participant group

14 The consent form must be signed (or thumb impressioned) by each prospective participant as evidence of informed consent

\begin{tabular}{lllll}
\hline 15 & $\begin{array}{l}\text { Investigators should justify any exceptions to this } \\
\text { general rule and obtain the approval of the ethical } \\
\text { review committee }\end{array}$ & $144(90 \%)$ & $2(1.2 \%)$ & $14(8.8 \%)$ \\
\hline 16 & $\begin{array}{l}\text { Efforts should be made not to recruit individuals who } \\
\text { are not capable of giving adequately informed } \\
\text { consent by reason of mental or behavioral disorders }\end{array}$ & $123(76.9 \%)$ & $6(3.7 \%)$ & $31(19.4 \%)$ \\
\hline 17 & $\begin{array}{l}\text { Guardians may give consent for individuals with } \\
\text { temporary disability }\end{array}$ & $121(75.6 \%)$ & $21(13.1 \%)$ & $18(11.3 \%)$ \\
\hline 18 & $\begin{array}{l}\text { However, once the patients are able to provide } \\
\text { consent, the form should be applied for their consent }\end{array}$ & $137(85.6 \%)$ & $6(3.8 \%)$ & $17(10.6 \%)$ \\
\hline 19 & $\begin{array}{l}\text { The participants should be informed about the } \\
\text { laboratory test results that influence the immediate } \\
\text { outcome/management of the health problem of } \\
\text { study participants }\end{array}$ & $114(71.2 \%)$ & $15(9.4 \%)$ & $31(19.4 \%)$ \\
\hline
\end{tabular}




\begin{tabular}{|c|c|c|c|c|}
\hline 20 & $\begin{array}{l}\text { Management/referral must be ensured in case of } \\
\text { abnormal test results }\end{array}$ & $130(81.2 \%)$ & 7 (4.4\%) & 23 (14.4\%) \\
\hline 21 & $\begin{array}{l}\text { Adequate time should be given to the participant to } \\
\text { decide if he/she is willing to participate }\end{array}$ & $144(90 \%)$ & $1(0.6 \%)$ & $15(9.4 \%)$ \\
\hline 22 & $\begin{array}{l}\text { The informed consent of each participant should be } \\
\text { renewed if there are significant changes in the } \\
\text { conditions/procedures of the research or if new } \\
\text { information becomes available that could affect the } \\
\text { willingness of participants to continue to participate }\end{array}$ & $126(78.8 \%)$ & $5(3.1 \%)$ & 29 (18.1\%) \\
\hline 23 & $\begin{array}{l}\text { In long term studies where repeated data collection } \\
\text { is required, the participants should be re-consented } \\
\text { at two years' interval, even if there are no changes in } \\
\text { the design or objectives of the research }\end{array}$ & $110(68.8 \%)$ & $17(10.6 \%)$ & $33(20.6 \%)$ \\
\hline 24 & $\begin{array}{l}\text { Two copies of the consent form are to be signed- one } \\
\text { for the research participant and the other one for the } \\
\text { investigator }\end{array}$ & $112(70 \%)$ & $16(10 \%)$ & $32(20 \%)$ \\
\hline
\end{tabular}

Table-2: Knowledge of the respondents regarding informed assent

\begin{tabular}{|c|c|c|c|c|}
\hline SL & Knowledge & $\begin{array}{l}\text { Agree/ } \\
\text { Yes }\end{array}$ & $\begin{array}{l}\text { Disagree/ } \\
\text { No }\end{array}$ & $\begin{array}{l}\text { Neutral/ } \\
\text { Not sure }\end{array}$ \\
\hline 1 & Consent and assent are same & $24(15 \%)$ & $76(47.5 \%)$ & $60(37.5 \%)$ \\
\hline 2 & Assent is taken from adults & $48(30 \%)$ & $72(45 \%)$ & $40(25 \%)$ \\
\hline 3 & Assent is taken from children aged $8-18$ years & $44(27.5 \%)$ & $66(41.2 \%)$ & $50(31.3 \%)$ \\
\hline 4 & $\begin{array}{l}\text { School headmaster or class teacher can give consent } \\
\text { for a student if he/she studies in the school }\end{array}$ & $52(32.5 \%)$ & $82(51.2 \%)$ & $26(16.3 \%)$ \\
\hline 5 & $\begin{array}{l}\text { In case of research with children (below the age of } 11 \\
\text { years), consent should be sought from the } \\
\text { parents/guardians }\end{array}$ & $153(95.6 \%)$ & $2(1.3 \%)$ & $5(3.1 \%)$ \\
\hline 6 & $\begin{array}{l}\text { In case of research with children aged } 11-17 \text { years, } \\
\text { assent should be sought from the children and } \\
\text { consent should be sought from the parents/guardians }\end{array}$ & $133(83.1 \%)$ & $7(4.4 \%)$ & $20(12.5 \%)$ \\
\hline 7 & $\begin{array}{l}\text { In case where parents/guardians' consent to } \\
\text { participate but children decline, the wish of the } \\
\text { children under such circumstances should prevail }\end{array}$ & $116(72.5 \%)$ & $20(12.5 \%)$ & $24(15 \%)$ \\
\hline 8 & $\begin{array}{l}\text { A parent/guardian who gives permission for a child to } \\
\text { participate in research should be given the } \\
\text { opportunity to observe the research as it proceeds }\end{array}$ & $117(73.1 \%)$ & $13(8.1 \%)$ & $30(18.8 \%)$ \\
\hline
\end{tabular}


Table-3: Knowledge of the respondents regarding genetic studies

\begin{tabular}{clccc}
\hline SL & Knowledge & $\begin{array}{c}\text { Agree/ } \\
\text { Yes }\end{array}$ & $\begin{array}{c}\text { Disagree/ } \\
\text { No }\end{array}$ & $\begin{array}{c}\text { Neutral/ } \\
\text { Not sure }\end{array}$ \\
\hline 1 & $\begin{array}{l}\text { In case of genetic study, participants should be informed } \\
\text { about the nature, outcome and consequences of the } \\
\text { study findings }\end{array}$ & $131(81.9 \%)$ & $12(7.5 \%)$ & $17(10.6 \%)$ \\
\hline 2 & Genetic test results must be revealed and clarified & $128(80 \%)$ & $11(6.9 \%)$ & $21(13.1 \%)$ \\
\hline 3 & $\begin{array}{l}\text { For genetic studies, provisions for pre-counseling must } \\
\text { be ensured }\end{array}$ & $141(88.1 \%)$ & $1(0.6 \%)$ & $18(11.3 \%)$ \\
\hline 4 & $\begin{array}{l}\text { For genetic studies, provisions for post-counseling must } \\
\text { be ensured }\end{array}$ & $130(81.3 \%)$ & $5(3.1 \%)$ & $25(15.6 \%)$ \\
\hline
\end{tabular}

\section{Discussion}

This study was carried out among 160 doctors pursuing postgraduate courses in different medical specialties in an institution located in Dhaka city, to appraise their knowledge about informed consent while conducting a research. In the present study, $90 \%$ of the medical professionals acknowledged the importance of an informed consent. It was expected that all the postgraduate students must be aware of the consent process. Our results were in accordance with studies conducted by Farhat et al. and Gupta et al. They found that $99 \%$ and $97.4 \%$ dental professionals knew that consent was as an integral part of research $[18,19]$.

The current study showed that $86.3 \%$ of the students agreed that verbal consent should not be taken. Similarly, Khare et al. showed that $95.7 \%$ had satisfactory knowledge about verbal consent while Gupta et al. had found that only $68.6 \%$ of the dentists had satisfactory knowledge about verbal consent $[4,19]$. According to this study, $85.6 \%$ students agreed that signed written consent was a must and only $5 \%$ agreed that verbal consent was the favorable method to obtain informed consent. A study by Mallela et al. revealed that $91 \%$ of medical researchers agreed that informed written consent should always include patient's signature [20]. Gupta et al observed that $48.7 \%$ of the dental professionals agreed that signatures should be taken even if it was a verbal consent. This may be because signature provides some evidence that patients have been informed in detail about the research and the consequences of the proposed treatment [19]. On the contrary, Farhat et al. found that among all types of consent, verbal consent (84.4\%) was found to be the favored method of acquiring consent over its written form [18]. However, all the ethical guidelines mention that written consent is a must except in very few instances e.g., interviewing sex workers [2].

In the current study, $92.5 \%$ agreed that informed consent was to be designed to empower the individual with information to make a voluntary informed decision regarding participation in a research. This was in accordance with the study conducted by Mallela et al. where $92 \%$ agreed that patients should be informed in detail regarding the research including risks and benefits [20]. However, a study from India reported that high percentage (90\%) of researchers believed that patients should not be told about potential risks of a study because that might hinder the participants to enroll in the study [21]. It is mandatory in research as per ethical guidelines to provide all the details including the pros and cons of the research to the research participants [22].

Informed consent protects the individual's freedom of choice and respects the individual's autonomy. An individual should take decision to participate without having been subjected to coercion, undue influence or inducement, or intimidation [22]. In the present study, $93.8 \%$ agreed that consent must 
ensure 'respect of the autonomy' and selfdetermination of all human beings, and acknowledge their dignity and freedom, as informed consent recognizes the capacity and rights of all individuals to make their own choices and decisions. Informed consent is based on the principle that competent individuals are entitled to choose freely whether to participate in research. In the present study, $24.4 \%$ were not aware that the principles of informed consent and voluntary participation were cardinal elements to be observed throughout the research experiments, including its aftermath. Autonomous choice and voluntariness is widely believed to be the key principle underlying consent according to ethical guidelines [23]. We found that $29.4 \%$ participants were not aware that research participants were to be continually kept informed of any and all developments in so far as they affected them and others.

Consent should be taken from all adult participants before the commencement of the study. Here, in the present study, $89.4 \%$ agreed that consent should be taken from adults while $45 \%$ participants were not aware that assent could not be taken from adults as $85 \%$ of the participants thought that consent and assent were not different. Assent should be sought from the children and consent should be sought from the parents/guardians in case of research with children aged 11-17 years [23]. In the present study, only $27.5 \%$ were aware that assent was taken from children. In this study, 95.6\% agreed that consent should be sought from parents/guardians in case of research with children (below the age of 11 years). Khare et al. observed similar findings where $91.4 \%$ had knowledge about assent for child participant [23]. Though 32.5\% agreed that school headmaster or class teacher of the child's school could not give consent for the child.

'Minors' (may be defined differently in different jurisdictions) are generally presumed incompetent to consent, but depending on their age and other factors may be required to provide informed assent. As children often lack the decision making ability or legal power (competence) to provide true informed consent for medical decisions, it often falls on parents or legal guardians to provide informed permission for medical decisions. The American Academy of Pediatrics encourages also seeking the assent of older children and adolescents by providing age appropriate information to these children to help empower them in the decision making process [24]. However, in the present study $27.5 \%$ responders were not aware of the age limit for assent. Some research guideline follows the 'Rule of Sevens' for children, which divides a child's life into three sections: birth to seven, seven to fourteen, and fourteen to twenty one years old. The 'Rule of Sevens' states that children under age 7 do not have the capacity necessary to make their own decisions; children from 7-14 years of age are presumed not to have this capacity until proven otherwise in individual cases, and children over age 14 are presumed to have capacity to make their own decisions and lead their own lives, unless proven otherwise [25].

Only $66.2 \%$ agreed in the present study that consent for participation in research should always be voluntary and informed. It should be accepted only if it is provided without any direct/indirect coercion and inducement, and is based on adequate briefing given to the participants about the details of the research [23]. More than $90 \%$ of the participants agreed that language of consent form should be understandable and must be signed by each prospective participant as evidence of informed consent.

According to the present study, $76.9 \%$ agreed that efforts should be made not to recruit individuals who by reason of mental or behavioral disorders are not capable of giving adequately informed consent. Guardians can give consent for individuals with temporary disability. However, once the patient is able to provide consent, re-consent should be taken from the study person [23]. In the present study, $75.6 \%$ agreed that guardians might give consent for individuals with temporary disability. However, Mallela et al. observed that $50 \%$ of the participants believed that certain vulnerable persons (e.g., mentally ill or children) could provide consent to participate in research [20]. Due to a serious illness/mental condition, an appropriate surrogate should make the decisions, ideally one who knows the patient's preferences and can therefore act in his best interest. The 
patient must be told what has been done and why, as soon as he has sufficiently recovered his mental faculties. A study by Munoli et al. suggested that $68 \%$ of medical professionals thought that if no surrogate was available to give informed consent for vulnerable groups, they could still be included [2]. This is contrary to the International Ethical Guidelines for Biomedical Research involving human subjects prepared by the Council for International Organizations of Medical Sciences (CIOMS) in collaboration with the World Health Organization (WHO) [2,22].

In the present study, $71.2 \%$ agreed that the participants should be informed about the laboratory test results that influenced the immediate outcome/management of the health problem of study participants and $81.2 \%$ agreed that management/referral must be ensured in case of abnormal test results. In case of any abnormal test results during the study management or referral must be ensured. As per ethical guidelines it is mandatory to take prior permission to perform any test from the sample and test results must be provided if it is useful for the treatment purpose of the participant. However, tests done later may not be given to the participants but this must be mentioned during collection of the sample. However, a test performed on anonymous samples is an exception [23].

In the present study, more than $80 \%$ of the participants agreed that for genetic studies, participants should be informed about the nature, outcome and consequences of the study findings, test results must be revealed and clarified, provisions for pre- and post-counseling must be ensured. Because of the complex issues and implications surrounding genetic testing, genetic counseling is often provided in the way of education, guidance, and pre- and post-test information about the risks, benefits, limitations, and implications of tests, as well as data storage and data usage (e.g., use in quality control or research) $[26,27]$. This approach facilitates patient consent to genetic testing and is viewed as a positive ethical feature. Indeed, evidence suggests genetic counseling improves knowledge and decreases anxiety, distress and depression [28]. Even so, concern remains about the lack of feasibility, applicability, or benefit to patients of receiving all of this information during the consent process. This is true for genetic testing in general, but especially relevant to broader genome analysis $[29,30]$. Others have gone further, and argued that too much detailed information can overload patient understanding [31,32] and undermine autonomous choice [33]. Though in our study, only $88.1 \%$ and $81.3 \%$ agreed for pre- and postcounseling respectively, but all genetic research must have provision for proper pre- and postcounseling.

The informed consent of each participant should be renewed if there are significant changes in the conditions and procedures of the research or if new information becomes available that could affect the willingness of participants to continue to participate. Re-consent is an action in which a participant makes the decision to participate in research once again in light of new information or change in research procedure(s) [34]. Though only $68.8 \%$ agreed in the present study but generally in long term studies where repeated data collection is required, the participants should be re-consented at two years' interval, even if there are no changes in the design or objectives of the research [35]. The limitation of our study is that it was a convenience sampling with small sample size. So the results cannot be generalized to the whole postgraduate doctors of medical science.

\section{Conclusion}

This study has concluded that informed consent is deemed as an integral part of the doctor and patient rapport. Knowledge and attitude should always run in a parallel way; once knowledge gets better, attitude will automatically improve. Although there is fair knowledge among postgraduate students; there is further need to initiate educational events to increase knowledge, awareness and acceptance of principles of research ethics among researchers. Faculty or students should be educated by holding seminars, workshops and continuing educational programs. The curriculum for students needs to be more detailed concerning research ethics. Thus, such initiative would further reduce the gaps of knowledge regarding informed consent and that may help in building constructive attitude towards necessity of consent process. 


\section{Conflicts of interest}

The authors declare that there is no conflict of interests regarding the publication of this article.

\section{Acknowledgments}

The authors are grateful to the study participants for their participation and kind cooperation throughout the study.

\section{References}

1. Normile D. The promise and pitfalls of clinical trials overseas. Science. 2008; 322(5899): 214-216.

2. Zimmerman C, Watts C. WHO ethical and safety recommendations for interviewing trafficked women. Geneva: World Health Organization; 2003.

3. Council for International Organizations of Medical Sciences (CIOMS). International ethical guidelines for biomedical research involving human subjects. Geneva: Council for International Organizations of Medical Sciences (CIOMS); 2002.

4. Khare A, Saxena V, Jain M, Sharva V, Singh P, Dayma $A$. Knowledge and attitude toward informed consent in medical and dental practitioners, of Bhopal city, India. J Dent Res Rev. 2017; 4(1): 17.

5. Sauer JE Jr. Ethical problems facing the healthcare industry. Hosp Health Serv Adm. 1985; 30(5): 44-53.

6. Irving DN. What is bioethics? In: Koterski JW. Life and learning $X$ : proceedings of the tenth university faculty for life conference. Washington, DC: University Faculty for Life; 2002. p. 1-84.

7. Beckerman N. Informed consent. In: Howarth G, Leaman O, editors. The Encyclopedia of Death and Dying. UK: Routledge; 2013.

8. Extended Project Dissertation; Can the lack of medical consent ever be justified? Available from: www.edexcel.com/.Medical20Consent-Feb.

9. Trials of war criminals before the Nuremberg military tribunals under control council law no.
10. 1949; US Government Printing Office, Washington 25, DC. 2: 181-182.

10. Marker AR. Doctors from Hell: The horrific account of Nazi experiments on humans. J Clin Invest. 2006; 116: 2.

11. Sharma R. Informed consent in clinical practice and research: ethical and legal perspective. Int J Healthcare Biomed Res. 2014; 3(1): 144-151.

12. Andre J. Bioethics as practice. Chaepel Hill: University of North Carolina Press; 2002.

13. Simon RI. Clinical psychiatry and the law. 2nd ed. Washington DC: American Psychiatric Press; 1992. p. 121e53.

14. Jonsen AR. The birth of bioethics. New York: Oxford University Press; 1998.

15. Widdos H, Dickenson D, Hellsten S. Global bioethics. New Rev Bioethics. 2003; 1(1): $101 \mathrm{e} 16$.

16. Nattinger AB, Hoffman RG, Shapiro R, Gottlieb MS, Goodwin JS. The effect of legislative requirements on the use of breast-conserving surgery. N Engl J Med. 1996; 335(14): 1035e40.

17. Bottrell MM, Alpert $H$, Fischbach RL, Emanue LL. Hospital informed consent for procedure forms: facilitating quality patient-physician interaction. Arch Surg. 2000; 135(1): $26 \mathrm{e} 33$.

18. Farhat W, Qiam F, Shah SM. Informed consent in dentistry: perceived importance and limitations in Khyber Pakhtunkhwa. J Khyber College Dent. 2013; 3: 14-19.

19. Gupta VV, Bhat N, Asawa K, Tak M, Bapat S, Chaturvedi P. Knowledge and attitude toward informed consent among private dental practitioners in Bathinda city, Punjab, India. Osong Public Health Res Perspect. 2015; 6: 73-78.

20. Mallela KK, Walia R, Tm CV, Das M, Sepolia S, Sethi $P$. Knowledge, attitudes and practice about research ethics among dental faculty in the North India. J Int Oral Health. 2015; 7: 52-56.

21. Munoli S, Niveditha G, Deepthi R. Knowledge, attitude and practice of research ethics among medical faculty in a teaching hospital. Int $J$ Basic Clin Pharmacol. 2017; 6(4). 
22. Council for International Organizations of Medical Sciences (CIOMS). International ethical guidelines for health-related research involving humans. Geneva: Council for International Organizations of Medical Sciences (CIOMS); 2016.

23. icddr,b. Ethical review committee guidelines. Dhaka: icddr,b; 2013.

24. Committee on Bioethics. Informed consent, parental permission, and assent in pediatric practice. Pediatrics. 1995; 95(2): 314-317.

25. Wendler DS. Assent in paediatric research: theoretical and practical considerations. J Med Ethics. 2006; 32(4): 229-234.

26. Reiff M, Mueller R, Mulchandani S, Spinner NB, Pyeritz RE, Bernhardt BA. A qualitative study of healthcare providers' perspectives on the implications of genome-wide testing in pediatric clinical practice. J Genet Couns. 2014; 23(4): 474-488.

27. Bernhardt BA, Biesecker BB, Mastromarino CL. Goals, benefits, and outcomes of genetic counseling: client and genetic counselor assessment. Am J Med Genet. 2000; 94(3): 189-197.

28. Kaphingst KA, McBride CM. Patient responses to genetic information: studies of patients with hereditary cancer syndromes identify issues for use of genetic testing in nephrology practice. Semin Nephrol. 2010; 30(2): 203-214.

29. Koenig BA. Have we asked too much of consent? Hastings Cent Rep. 2014; 44(4): 33-44.

30. Bradbury AR, Patrick-Miller L, Domchek S. Multiplex genetic testing: reconsidering utility and informed consent in the era of nextgeneration sequencing. Genet Med. 2015; 17(2): 97-98.

31. Grady C. Enduring and emerging challenges of informed consent. N Engl J Med. 2015; 372(22): 2172.

32. Brody BA. Making informed consent meaningful. IRB. 2001; 23(5): 1-5.

33. Bunnik EM, Janssens AC, Schermer $M H$. A tiered-layered-staged model for informed consent in personal genome testing. Eur J Hum Genet. 2013; 21(6): 596-601.

34. Resnik BD. Re-consenting human subjects: ethical, legal and practical issues. J Med Ethics. 2009; 35(11): 656-657.

35. Wallace SE, Gourna EG, Laurie G, Shoush O, Wright J. Respecting autonomy over time: policy and empirical evidence on re-consent in longitudinal biomedical research. Bioethics. 2015; 30(3): 210-217. 